\title{
An evaluation of the fermentation efficiency of selected substrates from the agri-food sector on a physical, chemical and biological basis
}

\author{
Monika Suchowska-Kisielewicz * \\ University of Zielona Gora, Institute of Environmental Engineering, Licealna 9, 65-417 Zielona \\ Góra, Poland
}

\begin{abstract}
Methane fermentation has been a waste management technique for years. The main advantages of fermentation include the production of electricity and heat from biogas or biomethane, which are a source of renewable energy. In order for the fermentation process to have good economic indicators, the continuous monitoring of process parameters is necessary. To control the fermentation process, an anaerobic test determining the biochemical methane potential (BMP) is particularly recommended. The disadvantage of this test is the long duration of measurements. Nowadays, AT4 respiration tests are increasingly used to assess the methane potential of waste. The main advantages of AT4 include: the 4-day duration of the test, the simple method for implementation and the possibility of applying the test to all types of waste. In practice, in most cases physical (VS) and chemical indicators (TOC and COD) are used to assess the suitability of substrates for fermentation and its effectiveness. However, these indicators specify only the total content of organic matter, yet do not give information on the fraction of biodegradable matter. The article presents an assessment of the efficiency of fermentation substrates selected from the agri-food sector on a physical, chemical and biological basis and presents the correlation between these indicators.
\end{abstract}

\footnotetext{
*Corresponding author : m.suchowska-kisielewicz@iis.uz.zgora.pl
} 


\section{Introduction}

Anaerobic digestion is one of the oldest biological processes that was used at a time when nothing was known about its microbiological foundations. In this process, high-molecular organic substances are broken down with the participation of various groups of bacteria, to simple compounds, mainly $\mathrm{CH}_{4}$ and $\mathrm{CO}_{2}$. In waste management, the fermentation process is used for the biochemical stabilization of waste, leading to their transformation into a harmless and easy to dehydrate substance. Methane fermentation as one of the stabilization methods is a process that has an advantage over others due to the possibility of using the produced biogas for energy purposes. An additional benefit of fermentation is the production of fertilizers and the reduction of greenhouse gas and odor emissions [1]. Biogas can be produced from a wide range of municipal waste as well as from the agricultural and food industry. Methane fermentation is recommended for the following groups of waste::

- sewage sludge,

- wastes from agriculture, horticulture, forestry, hunting and fishing: including vegetable waste, waste from energy crops, animal waste and droppings,

- wastes from the leather, fur and textile industries, from wood processing, production of boards, furniture and pulp, and sludges from on-site sewage treatment plants,

- organic biodegradable waste from the food industry (plant and animal waste),

- biodegradable fraction of municipal waste, including selectively collected fractions: household waste, bio-waste, paper and cardboard, green waste, and organic waste from craft enterprises.

Particularly attractive substrates for methane fermentation are waste from animal husbandry and agriculture.

They are characterized by a high biogas production potential and low purchase price. The fermentation of these substrates is a source of energy, and a method for their utilization and final management of digested sludge, e.g. as a fertilizer. The most developed agricultural branch is animal husbandry conducted on large farms. This leads to high pressure on the local environment, causing changes in the functioning of ecosystems. Therefore, it is extremely important that the management of animal waste in agriculture is carried out in a rational manner [2]. About 590,000 Mg of waste from meat processing and more than $377,000 \mathrm{Mg}$ of waste from fruit and vegetable processing are produced annually in Poland. Taking into account the average content of dry organic matter in these waste and their susceptibility to biodegradation about 60 million $\mathrm{m}^{3}$ of biogas can be obtained annually. However not all waste from the agri-food sector can be fermented on its own. This group of substrates includes waste with an unfavorable $\mathrm{C} / \mathrm{N}$ ratio or lignocellulose waste.

The methane fermentation of chicken manure requires balancing the $\mathrm{C} / \mathrm{N}$ ratio by introducing an appropriate amount of additional co-substrates, rich in organic carbon. A very good substrate rich in organic carbon may be lignocellulosic waste $[3,4]$.

Obtaining a high efficiency of co-fermentation of waste requires the constant monitoring of process parameters and control of the degree of loss of organic substrate in the fermented waste $[5,6,7]$.

In order to effectively assess the loss of organic matter during fermentation, biological indicators determining the level of biodegradable substance content should be used [8]. They include:

a. anaerobic tests, i.e .:

- BMP - biological methane potential - duration of the test up to 100 days,

- GS21 - total gas production - test duration 21 days,

- GB21 - assessment of biogas production - duration of the test 21 days, and respirometric tests, i.e .:

-AT4 - static respiration test - duration of the test 4 days, 
- DR4 or DR 100 - dynamic respiration test - duration of the test 4 and 100 days, respectively. Currently, volatile soild (VS) and total organic carbon (TOC) and chemical oxygen demand (COD) indicators are used to control the fermentation process. These indicators are easy to determine and give repeatable results, however, based on them, it is not possible to determine the contribution of the biodegradable fraction in the mass of organic matter, relevant information to assess the degree of stabilization of waste or the suitability of the substrate for fermentation and composting $[9,10,11]$. However, due to the ease of perform analysis, they are widely used in determining the substrate characteristics and efficiency of the fermentation process, although due to limited information on the degree of biodegradation of organic matter may be insufficient to assess the actual efficiency of the process [9, 10, 11]. Only the BOD indicator gives some information on the substrate biodegradability [10].

Reliable information in this area can be obtained on the basis of anaerobic biogas potential tests or respiratory tests. Both aerobic and anaerobic tests compared to physical and chemical indicators require specialized laboratory equipment and a longer analysis time. In order to improve the practicality of using these tests, scientists are currently looking for correlations between them, physical and chemical indicators, and between the BMP and AT4 parameters. Respiratory tests are increasingly used to assess the methane potential of waste [12]. The main advantages of this test include the short duration of measurements, a simple way to perform them and the possibility of applying the test to all types of waste [12]. Good correlations between BMP and AT4 have been designated by many authors but solely for municipal solid waste $[13,7,14,15]$. For waste from the agri-food sector, such correlations have not yet been determined.

The paper presents the results of research on the effectiveness of fermentation of chicken manure, maize silage, ground mushrooms, tomato blades, straw and their mixtures determined on the basis of potential of their methane production (BMP). Characteristics of the substrates used are presented on the basis of biological (AT4), physical (VS) and chemical (COD) indicators.

\section{Methodology and scope of research}

The waste, shredded to a size $<20 \mathrm{~mm}$ and applied in the research were:: chicken manure (CM), maize silage (MS), straw (S), surface of mushrooms and tomato haulms (TH). Mixtures with different percentages of waste were tested in three series. The mixture list is shown in Fig. 1-3.

The content of organic matter in waste and mixtures thereof was determined on the basis of VS and COD indicators. Biodegradability under aerobic and anaerobic conditions was determined based on AT4 and BMP tests. The tests were carried out in triplicate.

VS and COD assays were performed according to Standards Methods APHA (American Public Health Assotiation) methodology.

AT4 was performed on the static method using Oxi Top equipment $[16,17,18]$. Samples of waste were crushed to dimensions below $20 \mathrm{~mm}$ and brought to $40-50 \%$ humidity. The demand for oxygen was measured within 4 days after the adaptation stage (lag stage) in OxiTop devices. It was assumed that this stage ends when the average demand for oxygen during 3 hours reaches $25 \%$ of the 3 -hour average value occurring during the maximum increase in oxygen consumption during the first 4 days. The mass of oxygen consumed during the lag stage was subtracted from the mass of oxygen consumed during the whole test (lag stage +4 days). The mass of oxygen from the lag-stage cannot exceed $10 \%$ of the total demand for oxygen during the first 4 days (Fig.1).

Studies of the biochemical methane potential (BMP) of substrates were carried out in anaerobic reactors with a capacity of $2.5 \mathrm{dm}^{3}[19,20]$. The process was carried out for 21-30 days at $37^{\circ} \mathrm{C}$ (Fig. 2). Biogas from reactors was collected using a $300 \mathrm{ml}$ syringe. In the 
biogas was measured the following content: $\mathrm{CH}_{4}, \mathrm{CO}_{2}, \mathrm{O}_{2}, \mathrm{NH}_{3}, \mathrm{H}_{2} \mathrm{~S}$. The volume of biogas production and its composition at the beginning of the process were measured daily, and then depending on the volume of biogas production. In order to maintain optimal decomposition conditions, the contents of the reactors were mechanically mixed. The amount of substrate fed into the reactor was determined based on the assumption that from $1 \mathrm{~g}$ COD is obtained $395 \mathrm{ml}$ of $\mathrm{CH}_{4}$. -. The amount of inoculum was determined based on the VS of the substrate assuming that $1 \mathrm{~g}$ of VS inoculum per $1 \mathrm{~g}$ of VS inoculum [20].

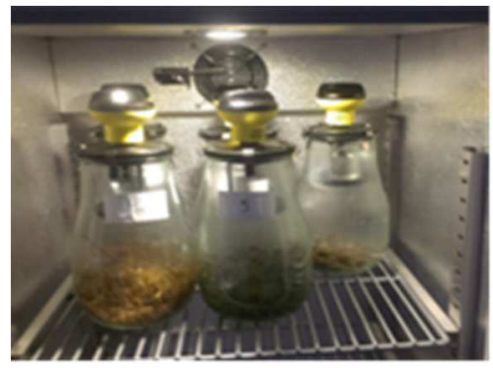

Fig. 1. The test bench - AT4.

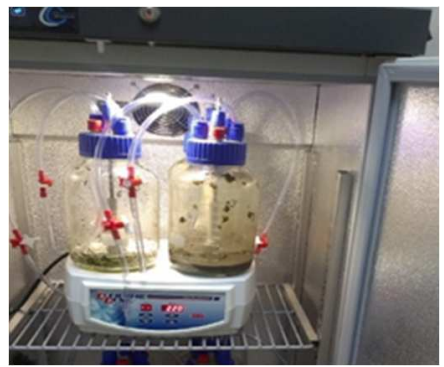

Fig. 2. The test bench - BMP.

\section{Results and discussion}

\subsection{Methane potential of the tested substrates}

The methane potential of the tested substrates and their mixtures is shown in fig. 3-5.

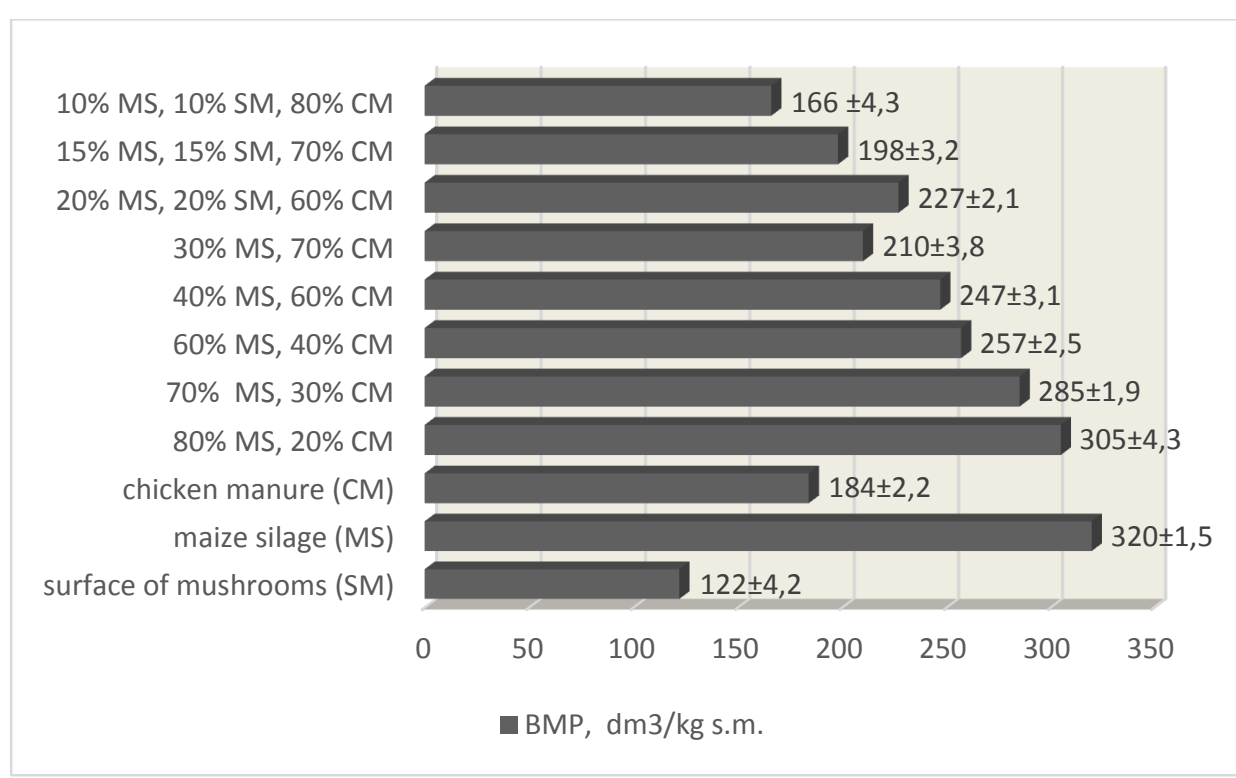

Fig. 3. Methane potential of chicken manure, maize silage and surface for mushrooms and their mixtures in various percentages (series I).

Analyzing the data presented in Figure 3, it can be concluded that the addition of corn silage (an easily degradable substrate with a high content of organic matter) to the chicken manure resulted in an increase in methane production in the range from 14 to $65 \%$ (the highest increase was recorded in mixtures with the chicken manure at 30 and $20 \%$ ). However, 
the addition of surface of mushrooms (lignocellulose waste) to the mixture of chicken manure with maize silage resulted in an increase in methane production for $60 \% \mathrm{CM}+20 \% \mathrm{MS}+$ $20 \% \mathrm{SM}$ and $70 \% \mathrm{CM}+15 \% \mathrm{MS}+15 \% \mathrm{SM}$ mixtures by only $24 \%$ and $14 \%$ respectively.

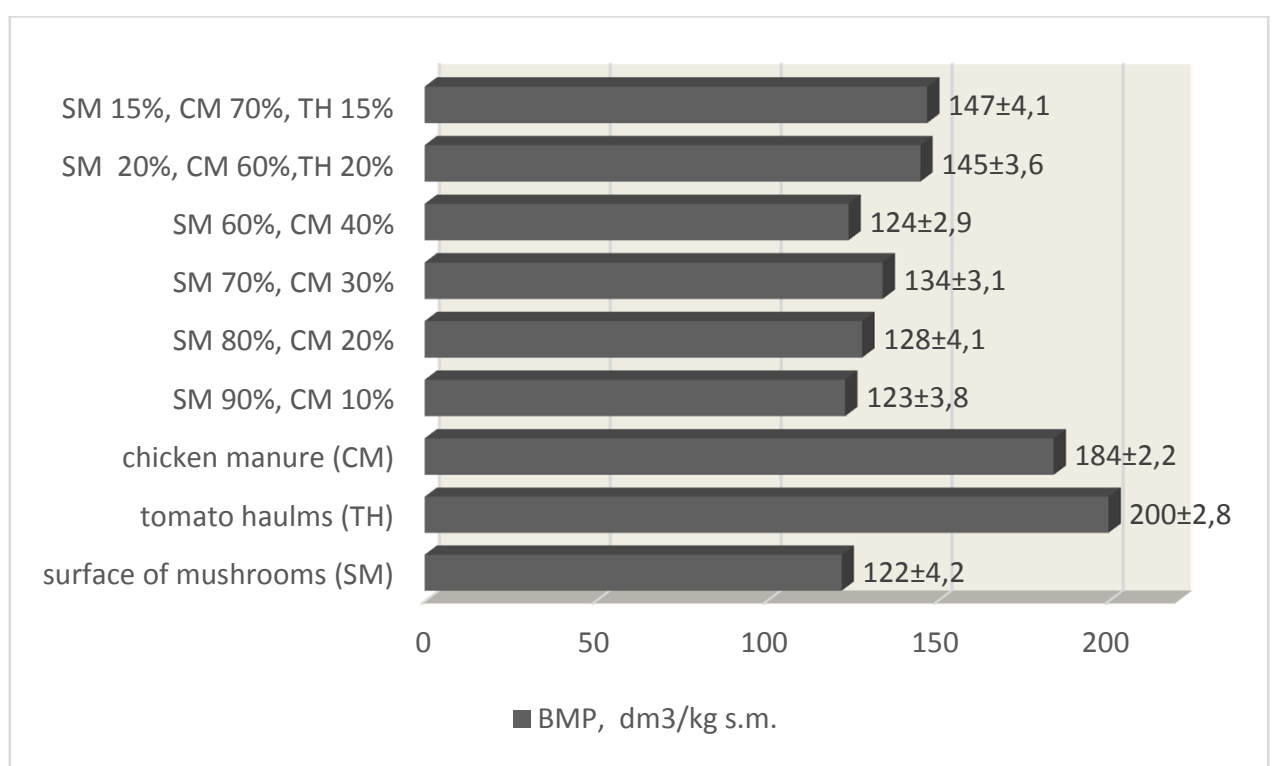

Fig. 4. Methane potential of chicken manure, tomato haulms and surface for mushrooms and their mixtures in various percentages (series II).

The co-fermentation of chicken manure and surface mushrooms with the participation of chicken manure in the range of 10 to $40 \%$ resulted in a decrease in the value of methane production (on average by $41 \%$ ) in relation to the value obtained for chicken manure, while in relation to the values obtained for the surface of mushrooms noted a slight increase about $4 \%$. An addition of tomato haulms (medium biodegradable substrate) to the mixture of chicken manure and surface of mushrooms caused about a $20 \%$ increase in the BMP value in relation to the values obtained for the surface of mushrooms (Fig. 4). 
S $15 \%$, CM $70 \%$, TH $15 \%$

S $20 \%$, CM $60 \%$, TH $20 \%$

S 10\%, CM 90\%

S $20 \%$, CM $80 \%$

S 30\%, CM 70\%

chicken manure (CM)

tomato haulms (TH)

straw (S)
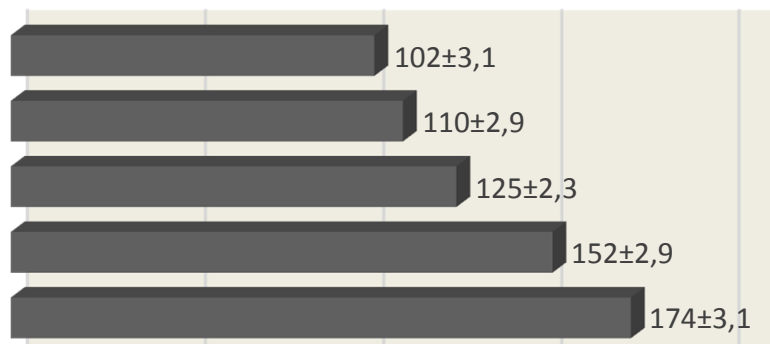

.
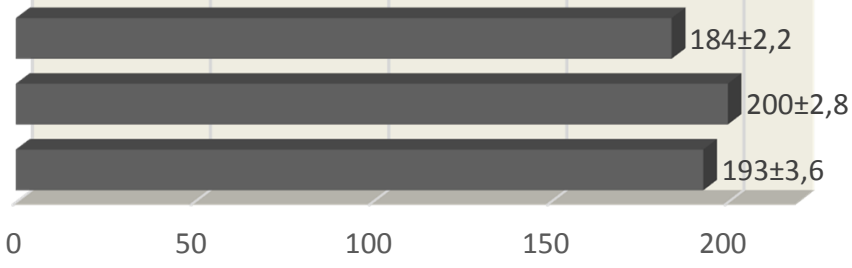

BMP, dm3/kg s.m.

Fig. 5. Methane potential of chicken manure, tomato haulms and straw and their mixtures in various percentages (series III).

The co-fermentation of chicken manure and straw (hard to biodegradable lignocellulosic waste), and chicken manure, straw and haulm tomatoes did not increase the production of methane in relation to individual substrates. The highest methane production at the level of $174 \mathrm{~L} / \mathrm{kgDM}$ was recorded for a mixture of $30 \% \mathrm{~S}+70 \% \mathrm{CM}$.

\subsection{Correlations between BMP and AT4, COD and VS indicators}

Table 1 presents mathematical equations describing the relationship between BMP and AT4, COD and VS indicators and their correlation coefficients $\mathrm{R}^{2}$.

Table 1. Features describing the relationship between the BMP indicator and the indicators AT4 BMP, COD and VS.

\begin{tabular}{|l|c|}
\hline Function & $\begin{array}{l}\text { Coefficient of } \\
\text { determination } \\
\mathbf{R}^{2}\end{array}$ \\
\hline \multicolumn{2}{|c|}{ SERIES I } \\
\hline $\mathrm{BMP}=1,311 \mathrm{AT} 4+69,124$ & 0,92 \\
\hline $\mathrm{BMP}=0,6355 \mathrm{VS}-257,77$ & 0,88 \\
\hline $\mathrm{BMP}=0,1741 \mathrm{COD}+14,023$ & 0,91 \\
\hline \multicolumn{2}{|c|}{ SERIES II } \\
\hline $\mathrm{BMP}=0,9367 \mathrm{AT} 4+82,981$ & 0,85 \\
\hline $\mathrm{BMP}=0,3137 \mathrm{VS}-59,789$ & 66 \\
\hline $\mathrm{BMP}=0,158 \mathrm{COD}+7,5659$ & 0,54 \\
\hline \multicolumn{2}{|c|}{ SERIES III } \\
\hline $\mathrm{BMP}=1,1411 \mathrm{AT} 4+69,415$ & 0,67 \\
\hline $\mathrm{BMP}=0,3318 \mathrm{VS}-86,466$ & 0,58 \\
\hline $\mathrm{BMP}=0,1015 \mathrm{COD}+65,148$ & 0,41 \\
\hline
\end{tabular}


Functions presented in Table 1 are characterized by a linear relationship with $\mathrm{R}^{2}$ determination coefficients in the range of 0.60-0.94.

The best correlations were obtained for the relationship between BMP and AT4 $\left(\mathrm{R}^{2}=\right.$ 0.67-0.91). These results confirm the literature data indicating that AT4 may be an index replacing the BMP parameter [12]. The main benefit of using the AT4 parameter is a significant reduction in the time of assessment of the suitability of substrates or mixtures for fermentation and the time of fermentation efficiency control. The lowest correlations between BMP and AT4 and BMP and VS and COD were recorded for mixtures of chicken manure and straw - a hardly biodegradable substrate. For this type of waste $\mathrm{BOD}_{5} / \mathrm{COD}$ ratio should be a better indicator for the assessment of biodegradation. Further tests will be carried out for this confirmation.

\section{Summary}

The article evaluates the suitability for fermentation of selected wastes from the agro-food sector based on biological indicators (BMP, AT4), physical (VS) and chemical (COD). The obtained research results allow formulating the following conclusions:

1. The highest efficiency of methane production was characterized by maize silage, and its use as a co-substrate in mixtures with chicken manure has resulted in an increase in methane production in the range from 14 to $65 \%$.

2. Co-fermentation of chicken litter with lignocellulosic waste (ground of mushrooms, straw) caused a drop in methane production an average of $41 \%$ and $31 \%$, respectively.

3. AT4 indicator is a parameter on the basis of which it is possible to assess the suitability of the substrate for fermentation and control its effectiveness.

4. VS and COD indicators can be used to assess the biodegradability of easily and medium-degradable substrates.

5. Further tests will be carried out to demonstrate the suitability of the BOD5 / COD quotient as an indicator of the biodegradation of medium and hard-to-decompose wastes.

\section{References}

1. A. Chiumenti, F. da Borso, S. Limina, Waste Manage., 71, 7 (2018)

2. J.R.Mroczek, Inż. Ekolog., 22, 8 (2010)

3. A. Jędrczak, Biologiczne przetwarzanie odpadów (PWN, Warszawa, 2007)

4. P. Carmona, K. Witaszek, Arch. Gosp. Odpad. i Ochr. Śr., 16 (1), 6 (2014)

5. R. Cossu, G. Fantinato, A. Pivato, A. Sandon, Waste Manage. 68, 8 (2017)

6. Y. Jin, T. Chen, X. Chen, Z. Yu, Appl. Energy, 151, 10 (2015)

7. L. Yangyang, J. Yiying, B. Aiduan, L. Hailong, L. Jinhui, Bioresource Technol.., 243, 10 (2017)

8. K. Bernat, M. Zielinska, A. Cydzik-Kwiatkowska, I. Wojnowska-Baryła, Biochem. Eng. J., 100, 11 (2015)

9. L. Chao, I. Ngesa, L. Wenjing, W. Haoyu, Bioresource Technol. 244, 9 (2017)

10. A. Schievano, G. D’Imporzano, V. Orzi, F. Adani, Bioresourse Technol. 102 (19), 6 (2011)

11. N. Cobo, A. López, A. Lobo, WIT Tran. Ecol. Envir., 109, 10 (2008)

12. P. Jin-Kyu, T. Kazuo, H. Sotaro, L. Nam-Hoon, Environ. Engn Res., 22(4), 8 (2017)

13. R. Cossu, R. Raga, Waste Manage., 28, 8 (2008)

14. B. Scaglia, R. Confalonieri, G. D’Imporzano, A. Fabrizio, Bioresource Technol., 1018 (2010) 
15. S. Wagland, S. Tyrrel, A. Godley, R. Smith, Waste Manage., 29, 9 (2009)

16. F. Adani, C. Ubbiali, Static and dynamic respirometric indexes - Italian research and studies. Biological treatment of biodegradable waste - Technical Aspects, Brussels (2002)

17. M. Bożym, Prace Instytutu Ceramiki i Materiałów Budowlanych, 7, 9 (2011)

18. B. Scaglia, M. Acutis, F. Adani, Waste Manage., 31(1), 8 (2011)

19. L. Jih-Gaw, M. Ying-Shih, C. Allen, H. Cheng-Lung, Bioresource Technol., 68 (2), 6 (1999)

20. W. Owen, D. Stuckey, J. Healy, J. Young, P. McCarty, Water Res., 13, 8 (1979) 